Revista Temas Socio Jurídicos

Vol. 37 No 75 Julio - Diciembre de 2018

pp. $92-129$

ISSN: 0120-8578

ISSN electrónico: 2590-8901

\title{
APLICACIÓN DE LOS INSTRUMENTOS INTERNACIONALES EN LA EJECUCIÓN DE LA PENA
}

Alicia Martínez Ulloa ${ }^{1 *}$

Recibido: Octubre 15 de 2018

Aprobado: Noviembre 30 de 2018

\section{RESUMEN}

Este artículo ofrece una guía de los documentos básicos que conforman la aplicación de los instrumentos internacionales mínimos para la protección de los matices positivistas de los derechos humanos de las personas privadas de la libertad. También se presenta la intervención de juez de ejecución de penas en el punto relacionado con el Estado de Cosas inconstitucionales a partir de normas ius-fundamentales, legales y reglamentarias vigentes en Colombia.

Palabras clave:Ejecución de la pena, personas en reclusión, juez de ejecución de penas, Estado de Cosas inconstitucionales, derecho penal, dignidad humana y hacinamiento carcelario.

\section{APPLICATION OF INTERNATIONAL INSTRUMENTS IN THE EXECUTION OF SANCTIONS}

\begin{abstract}
This article presents the need to offer a guide to the basic documents that make up the application of minimum international instruments for the protection of the positivist nuances of the human rights of persons deprived of their liberty. He also glimpses the intervention of the judge of execution of penalties in the point related to the state of unconstitutional things based on ius-fundamental, legal and regulatory norms in force in Colombia.
\end{abstract}

1* Abogada. Especialista en Derecho penal, Especialista en Derecho constitucional, Especialista en Derecho público, Magíster en Derecho penal. Profesora Universitaria. 
Key words: Execution of the penalty; people in detention; judge of execution of sentences; state of unconstitutional things; criminal law.

\section{APLICAÇÃO DOS INSTRUMENTOS INTERNACIO- NAIS NA EXECUÇÃO DA PENA}

\section{RESUMO}

Este artigo oferece uma guia dos documentos básicos que compõem a aplicação dos instrumentos internacionais mínimos para a proteção dos matizes positivistas dos direitos humanos das pessoas privadas de liberdade. A intervenção do juiz de execução de penas no ponto relacionado com o Estado de Coisas inconstitucional é também apresentada a partir de normas jusfundamentais, jurídicas, legais e regulamentares atuais na Colômbia.

Palavras-chave: Execução da pena, pessoas reclusas, Estado de Coisas inconstitucional, dignidade humana, superlotação carcerária.

\section{INTRODUCCIÓN}

Para empezar, es importante recordar que la figura del Juez de Ejecución de penas, como garante del respeto a los derechos fundamentales de las personas privadas de la libertad, surge con la actual Constitución política y desarrolla las funciones que en el decreto 2700 de 1991 se les ha encomendado, señaladas tanto en la ley 65 de 1993, artículo 7A, como en el artículo 38 de la ley 906 de 2004, en cuyos preceptos se le encomienda la vigilancia de las condiciones de la ejecución de la pena y las medidas de seguridad impuestas en la sentencia, así como también la concesión o no de los sustitutos penales y beneficios administrativos, entre otros.

En el cumplimiento de estas funciones es importante resaltar que la pena recae necesariamente sobre una persona, por lo tanto, el respeto por la dignidad humana juega un papel primordial en la delicada tarea que debe cumplir el vigía de la pena. En esta labor se deben tener en cuenta no solo los principios constitucionales de la materia, que a la postre se transmiten en las disposiciones de la ley 65 de 1993, en los artículos del 1 al 13, sino también, la ley 906 de 2004. Asimismo, también deben ser aplicados los instrumentos internacionales que, por la vía del bloque de constitucionalidad, artículo 93 de la carta política de Colombia, juegan un papel importante en la salvaguarda de la ejecución de la pena para las personas en estado de reclusión.

El manejo que se le ha dado a la ejecución de la pena en Colombia, desde el texto supremo de 1991, ha sido el resultado del progreso en la relación especial de sujeción, que inicialmente sirvió para explicar los alcances del 
principio de legalidad o las limitaciones posibles de los derechos ius-fundamentales de quienes se encontraban privados de la libertad.

\section{RELACIÓN ESPECIAL DE SUJECIÓN}

Este concepto se viene manejando desde el siglo XIX en Alemania, época con dificultades en el control de los espacios carcelarios, pues la cárcel era considerada un lugar sin ley de justicia penal. Razón por la cual se originaron las teorías de relaciones especiales de sujeción (Enterría Martínez-Carande, 2002); con las cuales se trató de explicar la relación jurídica existente entre el Estado y las personas privadas de la libertad, dando a estas últimas, un status jurídico reducido a una forma en extremo sencilla en la que todas las cosas se convierten en obligaciones y apenas se reconocen algunos derechos. Así lo señaló Mayer Otto (1982):

"Hay en el derecho público una clase especial de relaciones que contienen un poder general a favor de la autoridad: Se les ha dado el nombre de relaciones de sujeción particular." (Mayer, 1982, pág. 134)

Y más adelante agrega: "Sujeción significa vínculo de dos personas desiguales desde el punto de vista del derecho, cuyo contenido lo determina la voluntad de la persona superior." (Mayer, 1982, pág. 144)

Este concepto ha mejorado y ahora se reconoce que los prisioneros tienen un status jurídico particular: son considerados como sujetos titulares de derechos fundamentales, aunque con ciertas limitaciones derivadas de su situación de reclusos. Salomoni (1997) planteó una teoría de la sujeción de especial relación entre los reclusos y el Estado basada en tres principios:

i) Una máxima vinculación o un plus de vinculación del administrado a la administración producida por la relación de sujeción especial; ii) un déficit de legalidad que se torna legal por esa especial relación de sujeción; y iii) una disminución de los derechos fundamentales. (Salomoni, 1997, pág. 154)

Principios que en primera medida se aplicaron a los funcionarios públicos, los agentes de la policía, la milicia y estudiantes de instituciones oficiales; sin embargo, la evolución del derecho terminó por cubrir también a la población carcelaria. Cabe entonces el interrogante: ¿cuál es el significado actual de la relación de sujeción especial con el Estado que tiene el interno? Para responder, en primer lugar, traigamos a colación lo que la Corte Constitucional ha dicho:

A partir del vínculo que nace entre el Estado y las personas privadas de la libertad, definido por esta Corporación como de 'especial relación de sujeción', se justifica la capacidad de adoptar ciertas medidas sobre la población carcelaria sin desconocer con ello los criterios de razonabilidad, utilidad, necesidad y proporcionalidad, que conllevan al cumplimiento de una serie de lineamientos, recogidos en la sentencia T-049 de 2016: 
(i) La subordinación de una parte (los internos) a la otra (el Estado)

(ii) Esta subordinación se concreta en el sometimiento del recluso a un régimen jurídico especial, controles disciplinarios y administrativos, y la posibilidad de restringir el ejercicio de ciertos derechos, inclusive fundamentales.

(iii) Este régimen, en cuanto al ejercicio de la potestad disciplinaria especial y a la limitación de los derechos fundamentales, debe ser autorizado por la Carta Política y la ley.

(iv) La finalidad del ejercicio de la potestad y limitación en mención es la de garantizar los medios para el ejercicio de los otros derechos de las personas privadas de libertad, buscando cumplir con el objetivo principal de la pena, que es la resocialización.

(v) Como derivación de la subordinación, surgen algunos derechos especiales en cuanto a las condiciones materiales de existencia en cabeza de los internos.

(vi) El deber del Estado de respetar y garantizar el principio de eficacia de los derechos fundamentales, en especial con el desarrollo de conductas activas. (Corte Constitucional, Sala X, T-193, 2017)

Sobre este tema, la Comisión Interamericana de Derechos Humanos ha manifestado que a partir del vínculo que nace del interno con el Estado se constituye una relación jurídica de derecho público que se encuadra dentro de las categorías ius administrativistas. Esta se reconoce como relación de sujeción especial, en la que se dispone al Estado como el garante de aquellos derechos que mantiene el recluso a pesar de la privación de la libertad. Producto de dicha relación se crean deberes mutuos, cuyo objeto es ejercer la potestad punitiva en lo que al cumplimiento de la pena se refiere y simultáneamente garantizar el respeto por los derechos de la población carcelaria.

Vale mencionar que las personas que se encuentran privadas de la libertad se movilizan con libertad para lograr vivir con dignidad sus derechos ius fundamentales. Si bien es cierto que sus derechos humanos son aquellos que el Estado otorga en el orden jurídico, es decir, con matices positivistas de los derechos humanos como derechos fundamentales en la constitución de 1991, es claro que los derechos humanos constituyen mínimos de existencia y por ello serán respetados y promovidos. De ahí que ellos sean parte del derecho positivo y al estar integrado en el ordenamiento jurídico constitucional adquieren un carácter vinculante para la nación y existen remedios procesales para verificar su cumplimiento o subsanar su afectación, la jurisprudencia constitucional los clasifica en tres grupos:

i) derechos fundamentales que indudablemente como a la libertad física y a la libre locomoción y los derechos políticos son suspendidos como 
consecuencia de la pena de prisión) derechos como los de la intimidad personal y familiar, reunión, asociación, libre desarrollo de la personalidad y libertad de expresión sufren fuertes restricciones. iii)otro grupo de derechos, entre los cuales podemos encontrar algunos como la vida e integridad personal, la dignidad, la igualdad, la libertad religiosa, el derecho al reconocimiento de la personalidad jurídica, a la salud y al debido proceso, y el derecho de petición, mantienen su integralidad y contenido esencial intacto. (Corte Constitucional, Sala X, T-075, 2016)

Con el propósito de garantizar estos derechos surge la necesidad de ejercer controles sobre la actividad penitenciaria, no para controlar la administración, sino para controlar la esfera de la actuación estatal, el control de legalidad como cualquier ente del Estado. En estos casos se utiliza un control externo de tipo administrativo cuyos actos admiten al mismo tiempo un control por parte de Tribunales sentenciadores -control impropio o indirecto- y otro en donde el control está encargado a un órgano jurisdiccional, en Colombia sobresale el primero.

\section{INSTRUMENTOS INTERNACIONALES EN LA EJECU- CIÓN DE LA PENA EN EL ESTADO COLOMBIANO}

Con relación a lo anterior, los instrumentos internacionales juegan un papel muy importante no solo en la interpretación de la normatividad sobre los derechos fundamentales de las personas privadas de la libertad, sino que también en la la ejecución de la pena. En específico son:

1. Las Reglas mínimas para el tratamiento de reclusos. Fueron adoptadas en el primer congreso de las naciones unidas sobre la prevención de delito y tratamiento del delincuente celebrado en Ginebra en 1955 y aprobado más adelante por el Consejo Económico y Social.

2. Conjunto de principios para la protección de todas las personas sometidas a cualquier forma de detención o prisión. Fue adoptado por la Asamblea General en diciembre de 1988.

3. Principios básicos para el tratamiento de los reclusos. Adoptado por la Asamblea General en diciembre de 1990.

Estos tres instrumentos ofrecen un conjunto amplio de salvaguardias para la protección de los derechos de las personas que están detenidas o encarceladas. En suma, afirman que todos los presos y detenidos deben ser tratados de tal forma que se respete su dignidad humana, en relación con las condiciones de detención. El objeto de este artículo es la guía de documentos básicos que conforman la aplicación de instrumentos internacionales mínimos aplicados para las personas en estado de reclusión y la intervención del juez de ejecución de penas en relación con el estado de cosas inconstitucionales. Para ello se ha realizado una ardua revisión bibliográfica acerca de estas experiencias, que comenzó en la búsqueda de revistas 
indexadas en la base de datos y que se ocupan de las siguientes cuestiones: trato y disciplina, contacto con el mundo exterior, salud, clasificación y separación, quejas, registros, trabajo y ocio, religión y cultura.

Ha de indicarse que la regulación precedente no contempla el valor de un tratado internacional en cuanto a las formalidades de su aprobación e incorporación al derecho interno; sino que más bien son meras recomendaciones en principio carentes de posibilidad de vinculación. No obstante que han sido incorporadas en la jurisprudencia de la Corte constitucional como parte de las directrices que deben ser respetadas en el derecho penitenciario. De ahí que han servido de fundamento en reiteradas decisiones para resaltar las condiciones en los centros penitenciarios que se consideran violatorios de los derechos fundamentales, como se atisba en las sentencias T-879 de 2001, la T-851 de 2004, la T-1096 de 2004,la T-439 de 2006, la T-412 de 2009, entre otras.

Aclárese que la importancia de este documento es porque va a constituir el marco de referencia sobre el cual el Juez de ejecución de penas puede verificar la violación de los derechos fundamentales de las personas privadas de la libertad, principalmente el irrespeto a la dignidad humana.

\section{a) En cuanto al derecho a la integridad física y moral}

Los preámbulos de la Declaración Universal de Derechos Humanos y los dos Pactos Internacionales de derechos humanos destacan lo siguiente: la libertad, la justicia y la paz en el mundo tienen por base el reconocimiento de la dignidad, inherente a todos los miembros de la familia humana y de sus derechos iguales e inalienables.

El Principio 1 del Conjunto de principios para la protección de todas las personas sometidas a cualquier forma de detención o prisión dispone que: “Toda persona sometida a cualquier forma de detención o prisión será tratada humanamente y con el respeto debido a la dignidad inherente al ser humano".

Este principio queda confirmado en los Principios básicos para el tratamiento de los reclusos. En estas Reglas mínimas, adoptadas por las Naciones Unidas en 1995 y que tratan sobre las características esenciales de la vida cotidiana en prisión, se detalla lo que constituye el trato humano de los reclusos.

Sin embargo, luego de varias búsquedas sobre los principios, son pocas las investigaciones del tratamiento de los reclusos. En estas pesquisas los documentos de mayor importancia hablan del derecho a la integridad física y moral como valor supremo y fundamental; pero no se habla del mismo en el área de comprensión carcelaria. Pese a ello, y dado su aporte dentro de la investigación, es pertinente retomar algunos estudios importantes por la perspectiva frente a la democracia, en los que se vislumbra el tratamiento en estados latinoamericanos tales como Perú, Argentina y 
México, en donde se aporta una guía penitenciaria para el distrito federal, y el aporte de la defensoría del pueblo colombiano.

A continuación, se entrega un resumen y reseña de cada texto analizado con miras a rescatar los elementos más relevantes del análisis pretendido.

En cuanto al Derecho a la integridad física y moral, llama la atención el texto que lleva por título "El derecho a la integridad personal", en el que se encuentra una definición pertinente, pues se presenta como un conjunto de condiciones físicas, psíquicas y morales que le permiten al ser humano su existencia, sin sufrir ningún tipo de menoscabo en cualquiera de esas tres dimensiones (Afanador C, 2002). De ahí que la autora exprese la necesidad de mantener ligado el derecho a la integridad física y moral al derecho fundamental a la vida; por ser este, en palabras de la misma, el presupuesto sine qua non de "todos los derechos humanos" y por ende, debe ser entendido como la necesidad de no sufrir menoscabo corporal, psíquico y moral. La distinción entre el derecho a la integridad y el derecho a la vida tiene que ver con que este último se entiende en sentido estricto como el derecho de existencia.

En este mismo sentido, la autora desarrolla ciertos aspectos en el contexto fundamental y democrático de los derechos humanos:

desde la perspectiva del Estado social y democrático de Derecho, el concepto de persona humana hace referencia al individuo no como abstracción autónoma y aislada, sino en su dimensión social, como entidad que actúa necesariamente en el complejo de la vida sociopolítica inalienable.

Y este viene a ser el sentido más importante ya que en democracia es posible alcanzar una óptima protección de los derechos humanos.

Afanador realiza igualmente un recuento con los referentes de vulneraciones al derecho de la integridad personal, hablando específicamente de la tortura, su origen y evolución, la conceptualización jurídica, los sujetos del derecho, el contenido del derecho a no ser torturado, aspectos de la desaparición forzada y su presencia en América latina, para llegar a un análisis de la misma, en Colombia; va desde los conceptos jurídicos sobre desaparición forzada y bienes de la personalidad protegidos, para terminar con el contenido del derecho a no ser desaparecido.

En el siguiente texto analizado, "Apuntes sobre el derecho a la integridad en la constitución Peruana", se observa cómo el autor examina contenidos ius-fundamentales, consagrados en el inciso primero del artículo 2 de la Constitución peruana,; en relación con el derecho a la vida, y cómo también realiza un análisis de las dimensiones morales, físicas, psíquicas y las conductas lesivas (Sáenz Dávalos, 2015), revisando su reconocimiento como derecho, y las diversas aristas del derecho a la integridad moral, psíquica y física. Con tales herramientas se puede realizar un 
examen latinoamericano de espectro amplio de la situación en la región.

Otro documento que genera un aporte en el tema fue realizado en el área de trabajo social. Dicho texto reitera que la integridad es un derecho de orden fundamental, dándole su origen en el respeto a la vida y el sano desarrollo. En este trabajo se insiste en la idea de que estamos ante un derecho fundamental, por conexión con el de la vida, ya que hace parte de un conjunto de derechos que conforman un todo. Asimismo, hace referencia a los aspectos definitorios de la tortura, tratos crueles o denigrantes, y se plantea la integridad desde un contexto democrático, dejándonos la reflexión de que: "el mejoramiento en la defensa, protección y promoción de los derechos humanos, en particular de la integridad personal, sólo es posible con una verdadera profundización de la democracia” (Guzmán, 2007, p.7).

En el programa de derechos humanos del distrito federal de ciudad de México se busca, según el autor Solórzano Betancourt (2010), en El Programa de Derechos Humanos del Distrito Federal (PDHDF): "Respetar, proteger, promover y garantizar, bajo el principio de igualdad y no discriminación, el derecho a la integridad, a la libertad y a la seguridad personal de todas las personas que habitan y transitan en el Distrito Federal." (Solórzano Betancourt, 2010, pág. 5) Este documento se consideró importante porque enseña un parangón de las estrategias para velar por la integridad.

En cuanto a la libertad y la seguridad personal, la autora elabora una línea de acción en relación con estos derechos y los responsables de la aplicación e implementación de los mismos, acompasada con un programa de derechos humanos del distrito federal. Este folleto de corte institucional muestra las obligaciones adquiridas por esa nación, para lograr un seguimiento en la legislación y las políticas públicas. Esto permite adoptar una guía para analizar los resultados y se convierte en un mecanismo que facilita el seguimiento de dichas políticas (Solórzano Betancourt, 2010, pág. 13)

Seguidamente, se analizó el texto titulado "Derecho a la integridad personal en el sistema carcelario", cuyo aporte es la visión de los derechos fundamentales desde una óptica del sistema de Derechos Humanos Americanos y de Naciones Unidas en la Argentina, en donde los derechos son violentados dentro de los centros de reclusión y a través de la práctica de la tortura. En el artículo las autoras concluyen que todo el sistema tiene un punto de encuentro al reconocer, amparar y regular el derecho a la integridad personal, principalmente al prohibir la tortura, e invitan a la consecución de un ordenamiento "interno de normas que prohíban o en todo caso sancionen la comisión de la tortura dentro del sistema carcelario." (Duarte, Paz, \& Sueldo, 2016, pág. 327)

Tras la incorporación de los tratados internacionales en este país, se tipificó la tortura como delito y se desarrolló el sistema de protección con 
la ley $\mathrm{N}^{\mathrm{a}}$ 26.827, que habla sobre el Sistema Nacional de Prevención de la Tortura y Otros Tratos o Penas Crueles, Inhumanos o Degradantes. (Duarte, Paz, \& Sueldo, 2016, pág. 21)

Colombia cuenta con un documento elaborado por la Defensoría del Pueblo que abarca también los contenidos del derecho a la integridad personal, la protección internacional, y la protección nacional. Para el autor del texto es importante resaltar a los derechos humanos como una de las más grandes victorias de la humanidad; de ahí que se traten de una condición inalienable e imprescriptible, en sí latente por el solo hecho de ser personas o por su existencia.

La Defensoría del pueblo tiene el deber de impulsar por todo el país proyectos relacionados con los derechos humanos, trabajo que debe realizado de manera flexible para poder introducir contenidos. Con este fin se usa un manual de casos, un glosario de términos y una guía pedagógica, soportados en parámetros de doctrina y jurisprudencia. Dicho manual también trata del modo de incorporación a la constitución nacional y pese a ello, se observa que aun cuando se tienen tantos elementos comunes, nada dice sobre los procesos carcelarios, dando a entender que estos derechos quedan restringidos por la condena, o no se aterrizan a la realidad carcelaria. (Cifuentes Muñoz, 2001, pág. 7)

Por último, en el texto de "Contenido del derecho a la integridad personal" el autor pretende crear una herramienta que contenga las diferentes interpretaciones y decisiones emitidas por los distintos organismos internacionales especializados en esta materia, tanto en el sistema universal como en el sistema regional de protección de los derechos humanos, para de esta manera crear un corpus jurisprudencial y doctrinal sobre algunos vacíos conceptuales existentes en la actualidad sobre este tema. (Galindo, 2009, pág. 111)

Del texto se rescata el hecho de que los estados están en la obligación de prohibir en su legislación interna todo tipo de actos violatorios de los derechos humanos, así como deben investigar y sancionar a los autores materiales o intelectuales de actos que atenten contra la integridad física, psíquica o moral de las personas. En consecuencia, los estados pueden y deberían indemnizar a las víctimas y a sus familiares por los daños causados, y ellas pueden apelar incluso ante distintas instancias internacionales para responsabilizar a los gobiernos por su negligencia o incompetencia. En virtud de la analogía, es viable trasladar la rigurosidad de los aportes previamente mencionados a campos carcelarios o penitenciarios, y resulta importante, puesto que el responsable del cuidado, aplicación y cumplimiento del derecho a la integridad personal es el Estado, que ejerce su acción coercitiva para la garantía de los fines esenciales del mismo y por ello se somete a una dualidad que lo hace garante, no solo 
de la sanción, sino de garantizar a quienes han sido sometidos a la política criminal, los derechos que tan atentamente se han constituido. (Galindo, 2009, pág. 125)

\section{b) Prohibición de la tortura y los malos tratos}

Las reglas relativas a la prohibición de la tortura, así como los malos tratos provienen de la ratificación de Convenios sobre derechos humanos, en particular, aquellas que fueron establecidas por la Organización de Naciones Unidas en la Declaración Universal (1945), Igualmente, así como aquellas que protegen los derechos civiles y políticos de los habitantes del Estado. El marco jurídico que establece tal protección, se puede resumir en:

1. Las prohibiciones de la tortura y los malos tratos contenidas en el artículo 5 de la Declaración Universal de los Derechos Humano,

2. En la Convención contra la Tortura y otros tratos o penas crueles, inhumanos o degradantes -Parágrafo 1 del $\operatorname{art}^{\circ}$ primero (1)-,

3. En el artículo 7 del Pacto Internacional de Derechos civiles y Políticos

4. En el principio 22 del Conjunto de Principios para la protección de todas las personas sometidas a cualquier forma de detención o prisión y

5. En la regla 44 de las reglas mínimas para el tratamiento de los reclusos.

Los anteriores instrumentos internacionales son inequívocos frente a la imposibilidad de justificar la tortura o los tratos o penas crueles, inhumanas o degradantes, pues la definición de tortura es amplia e incluye cualquier forma de dolor o sufrimiento, sea físico o mental y distinto a la detención o el encarcelamiento.

Bajo ese entendido:

- Los reclusos nunca deben ser golpeados o sometidos a castigos corporales.

- No pueden infligirse castigos corporales como infracciones disciplinarias.

- Sólo puede recurrirse al uso de la fuerza cuando sea indispensable para contener a un preso.

- Debe capacitarse al personal en métodos no violentos para tratar con presos difíciles.

- En el desempeño de sus funciones, el personal debe actuar siempre en el marco de la ley.

- El personal declarado culpable de torturar o infligir actos de violencia injustificados a los presos debe ser perseguido y sancionado de conformidad con la ley. 
Sin embargo, después de analizar un poco más de 17 artículos, que estudiaron asuntos relacionados con esta temática, se puede establecer que: la violencia en centros penitenciarios, en forma de motines y enfrentamientos, puede darse por situaciones de hacinamiento (Sancha, 1992); que la escasez de recursos no solo para actividades o de materiales, sino en servicios de alimentación, higiene, medicina y salubridad es una forma de tortura (OIP, 1996); y que las consecuencias objetivas de las peleas o enfrentamientos entre internos y empleados son otra de las tantas formas de violencia (Rosales, 1997).. Al final, se añadieron al análisis dos estudios realizados por los profesores e investigadores José Ignacio Ruiz y Darío Páez Rovira, en los años 1999 y 2002. El primero es uno exploratorio en el que se comparan los efectos psicosociales en cinco centros penitenciarios. (Ruiz, 1999) En el segundo, se encontró en una muestra de empleados de prisiones que dos de los cinco sucesos que mostraban correlaciones directas más fuertes, con índice de malestar emocional, fueron haber sido golpeados, o ver golpear a otros en reclusión y hasta haber participado o sentir la experiencia de los enfrentamientos, peleas colectivas o motines con armamento en la prisión. (Rovira, 2002)

\section{c) Ingreso y puesta en libertad}

Las personas privadas de su libertad serán retenidas en lugares de detención oficialmente reconocidos. Se mantendrá un registro detallado de todas las personas privadas de libertad.

Todos los presos recibirán inmediatamente información escrita sobre las normas que rigen su trato y sobre sus derechos y obligaciones. Las familias, los representantes legales y, si procede, las delegaciones diplomáticas de los presos recibirán información completa sobre el hecho de su detención y sobre el lugar en el que están detenidos.

Se ofrecerá a toda persona detenida o presa un examen médico apropiado con la menor dilación posible después de su ingreso en el lugar de detención o prisión. Contenido lo anterior en la regla 7 de las reglas mínimas para el tratamiento de reclusos, en la regla No. 35 ibídem; en el principio No. 13 del conjunto de principios para la protección de las personas sometidas a cualquier forma de detención o prisión.

Significa lo presente que el reconocimiento de la dignidad humana comienza en el momento en que el preso es admitido por primera vez en la prisión. Un dato que resulta de gran interés en la puesta de libertad de las personas que estaban privadas de esta es el entorno socio-familiar. En la revista Anuario de Psicología Jurídica se aborda este principio como un instrumento que aumenta las posibilidades de recuperación de cualquier delincuente (joven o adulto). En la medida en que, si un joven cuyo primer delito es poco grave y posee buen apoyo familiar, el pronóstico de la libertad será favorable. Entonces al momento de contemplar el apoyo 
familiar positivo, se hace referencia a que su grupo familiar responsabiliza al interno ante el delito cometido y no le cubre o protege. Del mismo modo, el artículo en cita puntualiza que el apoyo familiar estable es el que se mantiene en el tiempo; en el resultado de la investigación encontraron que a veces se encuentra un apoyo familiar positivo, pero por el contrario no es un apoyo familiar estable (Rocío, 2009). En esa línea cuando el interno tiene más de 40 años y existe profesionalización delictiva, habitualmente carece de entorno familiar o social, dado que con el transcurso de los años ha ido perdiendo contacto con el mundo exterior, debido a la multitud de ingresos.

En esa medida, las vías de asociaciones que el vigía de la pena determine son importantes para que disfrute los beneficios penitenciarios y el apoyo conjunto del equipo o cuerpo de trabajo social del centro de reclusión.

\section{d) Derecho a una calidad de vida adecuada}

Toda persona privada de la libertad será tratada humanamente en aras de procurar la indemnidad del valor y principio de la dignidad humana, desde luego considerando la amplitud del respeto que tal resorte comprende.

Los razonamientos vertidos del anterior precepto legal tienen un fundamento normativo respetable, por lo que resulta prudente mencionar el contenido jurídico contemplado en el art. 25 de la Declaración Universal de los Derechos Humanos. En el pacto Internacional de derechos políticos y civiles en sus artículos 10 y 11 también se hace mención, respecto de este último también en su parágrafo 2 y terminado en las directrices y medidas para la prohibición y la prevención de la tortura y los tratos o penas crueles, inhumanos o degradantes en África, conocidas generalmente como las directrices de Robben Island.

Cabe mencionar que la privación de alimentos y agua en una cantidad suficiente, así como de vestidos y de alojamiento apropiados, a menudo pueden ser vistos como malos tratos a los presos, cuestión que puede ser considerada tortura en los peores casos. Finalmente, es importante saber que infligir tortura física o un trato cruel, no es la única forma de infringir las directrices de Robben Island.

En un Estado social de derecho como Colombia, el trasplante del complejo industrial carcelario a finales del siglo XX introdujo arquitecturas carcelarias, tecnologías de control y regímenes disciplinarios represivos que anulan las subjetividades, los vínculos sociales y familiares, y someten los cuerpos de las personas a dominación absoluta con la excusa de mantener la «seguridad en los penales (de Dardel, 2015)

FCSPP, 2012). Esta recomposición del campo penitenciario ha significado el incremento de la población carcelaria, la construcción de más prisiones y la degradación de las condiciones de vida en los penales. El complejo 
industrial carcelario no solo refleja la hipertrofia penal del Estado, sino la expansión de umbrales de muerte en contra de aquellos cuerpos excluidos por el mercado y marginados de la política asistencial estatal (Wacquant, 2010) (Ariza, 2011)

Estos espacios de poder, que producen la desacralización del cuerpo y su sometimiento a condiciones de destrucción, son propios del ejercicio del poder necrótico. La cárcel, haciendo eco de los argumentos de Mbembe, es un rmundo de muertes en el que se producen formas únicas y nuevas de existencia social, en las que numerosas poblaciones se ven sometidas a condiciones de existencia que les confieren el estatus de muertos-vivientes (Mbembe, 2011, págs. 74-75)

Es factible entonces sostener el argumento de que en las cárceles de Colombia se ha configurado un campo necropolítico que expone a umbrales de muerte, tanto física como social, a las personas privadas de la libertad. Esta idea fue desarrollada en el trabajo investigativo "Cárceles de la muerte: necropolítica y sistema carcelario en Colombia" de Bello, J. A y Parra, G. (2016). Durante la investigación se analizaron de manera crítica los informes sobre derechos humanos en las cárceles, empleando categorías interpretativas del black feminism, como el complejo industrial carcelario y la interseccionalidad, para señalar que en las cárceles opera una racionalidad que excede la biopolítica, instalando la muerte y la deshumanización como elementos cotidianos de su funcionamiento. (Bello \& Parra, 2016)

\section{d) Alojamiento}

Las estructuras físicas destinadas a los reclusos deberán proporcionar un volumen suficiente de aire, superficie mínima, alumbrado, calefacción y ventilación. Igualmente, cuando los presos ocupen dormitorios colectivos tendrán que ser cuidadosamente seleccionados y sometidos a vigilancia nocturna.

Tal reglamentación se vislumbra en el art. 16 de la Convención contra la Tortura y otros tratos o penas crueles, inhumanos y degradantes; en las Reglas Mínimas para el tratamiento de los reclusos, es decir, en la regla 9 inciso 1 y 2 , en la regla 10, en la regla 11 literal a) y b) y en la regla 26 inciso 1; en el apartado c); y por último, en las directrices de Robben Island en África.

Por lo discurrido, la sobreocupación de las instalaciones donde se alojan los presos es uno de los mayores problemas en muchas cárceles. Esto implica que dos o tres personas vivan en celdas originalmente previstas para una sola persona. En Colombia, un gran número de reclusos se encuentran hacinados en pequeños dormitorios, con un número insuficiente de camas, o sin colchones o ropa de cama adecuada. 
En conclusión, no existe una norma universal para el área de alojamiento de los detenidos ${ }^{2}$. Sin embargo, algunas organizaciones y en algunos foros, se han hecho recomendaciones para distintos grupos de países, por ejemplo:

"La Declaración de Kampala sobre las condiciones penitenciarias en África, de 1996, establece que los detenidos 'deben vivir en condiciones compatibles con la dignidad humana' y que las condiciones en las que son mantenidos los reclusos 'no deben agravar el sufrimiento que de por sí provoca la pérdida de la libertad”" (UNODC, 1996, pág. 42)

El principio XII de la Comisión Interamericana de Derechos Humanos (CIDH), en lo articulado con la Resolución 1/108, Principios y Buenas Prácticas sobre la Protección de las Personas Privadas de Libertad en las Américas, señala la capacidad de alojamiento como una mera guía del cumplimiento de las normas sanitarias.

Ahora bien, en reseña histórica y por falta de normas universales, varios países establecieron sus propias normas nacionales, las cuales presentan grandes diferencias. Por ejemplo, las normas europeas varían desde un espacio de $4 \mathrm{~m} 2$ en Albania a $12 \mathrm{~m} 2$ en Suiza. Algunas jurisdicciones exigen un mayor espacio para los detenidos en prisión preventiva, otras exigen más espacio para las mujeres (por ejemplo, Islandia, Polonia y Eslovenia), y otros países siguen diferenciando a los adultos de los delincuentes juveniles (por ejemplo, Hungría y Letonia) (Walmsley, 1997).

En el sur del continente americano, en Chile, se especifica un área de alojamiento de $6 \mathrm{~m} 2$ que incluye una cama individual, una ducha, un lavabo, un escritorio y un estante. En Guatemala, existen tres tipos de celdas: las celdas individuales miden $11,52 \mathrm{~m} 2$; las celdas para tres personas miden $20,68 \mathrm{~m} 2$, con un promedio de $6,98 \mathrm{~m} 2$ por persona; y las celdas colectivas para 37 detenidos miden $276,35 \mathrm{~m} 2$, con un promedio de 7,46 $\mathrm{m} 2$ por persona. Estas dimensiones incluyen el espacio para retretes y duchas. Estos requisitos mínimos de espacio no están específicamente establecidos por las leyes ni por los reglamentos.

En África, el alojamiento en dormitorios es la norma. En Kenia, el requisito de espacio mínimo es de 40 pies cuadrados $(3,7 \mathrm{~m} 2)$ por detenido. En Senegal no se especifica un espacio mínimo, pero un estudio interno reveló que el área de suelo promedio es de 3,55 $\mathrm{m} 2$ por persona, con una capacidad de $5 \mathrm{~m} 3$.

2 De acuerdo con la Oficina del Alto Comisionado de las Naciones Unidas (1977). Reglas mínimas para el tratamiento de los reclusos. Obtenido de: https://www.ohchr.org/sp/ professionalinterest/pages/treatmentofprisoners.aspx. Las RMPTR, en su artículo 10: "Los locales destinados a los reclusos y especialmente a aquellos que se destinan al alojamiento de los reclusos durante la noche, deberán satisfacer las exigencias de la higiene, habida cuenta del clima, particularmente en lo que concierne al volumen de aire, superficie mínima, alumbrado, calefacción y ventilación." 
Así mismo en Mauricio, el requisito de espacio per cápita es de $8,75 \mathrm{~m} 2$ en una celda individual, de $4,08 \mathrm{~m} 2$ en dormitorios para 20 personas y de 5,58 m2 en una sala de hospital. En Colombia, el Decreto 040 de 2017 en su artículo 2.2.1.13.1.3. "Especificaciones de infraestructura", en compartimiento armónico con el numeral 16 del artículo 2 del Decreto 4151 de 2011 "Funciones", autoriza al Instituto Nacional Penitenciario y Carcelario IPEC a determinar las necesidades en materia de infraestructura para una adecuada prestación de los bienes y servicios de las personas privadas de la libertad y obtener los suministros por parte de la Unidad de Servicios Penitenciarios y Carcelarios SPC. Empero, no deja claros los requisitos de espacio. En aquellos países que aplican normas mínimas, su cumplimiento es cada vez más difícil como consecuencia del incremento constante de la población carcelaria.

Es por ello que la Asociación Correccional de Estados Unidos ha publicado las Normas para instituciones correccionales de adultos, que establecen disposiciones espaciales para la ocupación de una celda individual (35 pies cuadrados/ 3,25 m2) y para la ocupación de celdas compartidas (25 pies cuadrados/ 2,32 $\mathrm{m} 2)^{3}$. Muchas jurisdicciones mencionan otras variables, tales como horas de confinamiento por día y el grado de supervisión, como factores relevantes para determinar lo que se considera espacio suficiente. En Australia, el estado de Victoria especifica $8,75 \mathrm{~m} 2$ para una celda individual con una ducha y un retrete, $6,5 \mathrm{~m} 2$ para una celda individual sin ducha ni retrete y $12 \mathrm{~m} 2$ para las celdas diseñadas para dos ocupantes ${ }^{4}$.

En las Reglas Penitenciarias Europeas (RPE) no especifican los requisitos mínimos de espacio, capacidad y ventilación. Sin embargo, el comentario sobre las RPE remite al Comité Europeo para la Prevención de la Tortura (CPT).

El CPT exige "un espacio mínimo absoluto de 4 metros cuadrados para los detenidos en celdas compartidas y de 6 metros cuadrados para los detenidos alojados en una celda individual" en todas las circunstancias, pero agrega que en casos particulares este requisito mínimo puede ser mayor, lo que depende "de la calidad del espacio y de la cantidad de tiempo que los reclusos tengan que pasar en su celda". En el acápite se añade que "si bien el CPT nunca consignó esta norma de manera expresa, existen indicios que sugieren que el CPT considera que el tamaño conveniente para una celda individual debería ser de 9 a 10 m2"5. (Drenkhahn, 2015, pág. 115)

Finalmente, no se puede decir que el Comité Internacional de Cruz Roja

3 "El espacio libre de obstáculos es el espacio utilizable no ocupado por muebles o enseres". Asociación Correccional de Estados Unidos, Adult Correctional Institutions, $4^{\text {a }}$ edición, 2003, p. 36.

4 Normas Australianas para el Diseño de Cárceles, Correctional Services Administrators Council, 2005.-

5 Consejo de Europa (2005) comentarios sobre la Regla 18. 
(CICR) haya establecido normas mínimas; sino que propone un conjunto de medidas específicas, por su ardua experiencia por más de 60 años en diferentes países. En cuanto al punto relacionado con el requisito de espacio físico en los centros de reclusión de las personas privadas de la libertad, consignado en un manual, vale la pena mencionar al autor Nembrini (2011) con el título: "Agua, saneamiento, higiene y hábitat en las cárceles". (Nembrini, 2011)

En diversas mesas redondas de la $\mathrm{CICR}^{6}$, por las disputas de las medidas de un espacio mínimo para una celda individual y un espacio mínimo para las celdas compartidas o múltiples, se llegó a una conclusión por unanimidad. El siguiente cuadro y la gráfica son el resultado final (siguiente página).

En báculo de lo expuesto, el órgano de cierre de lo Constitucional declaró cosas inconstitucionales en la sentencia T-153 de 1998 y T-388 de 2013, señalando el hacinamiento como parámetro elemental de discusión, que más adelante desarrollaría con más objetividad en la sentencia T-762 de 2015.

A pesar de que existe un auge investigativo, tanto académico como no académico, de los actos violentos, de inmersión, subestimación y desvalorización, ejercidos por los más fuertes hacia el débil; de las escenas de abusos sexuales y físicos como medio de aliviar la tensión; de enfermedades de alto riesgo y de contagio como amenaza creciente para la salud y desde luego para la dignidad humana de los reclusos en hacinamiento que permanecen por largos periodos en las cárceles, no se pueden extraer aún conclusiones científicas irrefutables en torno al tema. Debido a que en Colombia hay escasez en materia investigativa de los aspectos jurídicos del hacinamiento en relación con la dignidad humana, el comportamiento de los reclusos, las perspectivas del derecho comparado y el marco normativo internacional aplicado a políticas públicas en busca de superar ese estado de cosas inconstitucionales.

\section{e) Derecho a suficiente alimento y agua de bebida}

Los alimentos y el agua de bebida en cantidad suficiente dentro de las cárceles se conciben como parte de los derechos humanos, pues todos los presos tienen derecho a recibir alimentos nutritivos y en cantidad suficiente a horas regulares, con agua potable siempre que la necesiten.

Derechos humanos protegidos por el art. 11 del Pacto Internacional de Derechos Económico, Sociales y Culturales, al mismo tiempo que en el parágrafo 2 se dispone que los Estados parte reconocen el derecho fundamental de toda persona a estar protegida contra el hambre.

Sin embargo, el derecho a una alimentación adecuada es desarrollado en amplitud y con más detalle en la observación general No 12 en 1999 por el Comi- 


\begin{tabular}{|l|l|l|l|}
\hline Alojamiento & $\begin{array}{l}\text { Servicios sani- } \\
\text { tarios }\end{array}$ & Capacidad & Medidas \\
\hline Individual & No incluye & 1 persona & $5,4 \mathrm{~m} 2$ \\
\hline $\begin{array}{l}\text { Celda múltiple o } \\
\text { compartida }\end{array}$ & $\begin{array}{l}\text { Si incluye (in- } \\
\text { cluyendo hasta } \\
\text { literas) }\end{array}$ & 10 personas & $3,4 \mathrm{~m} 2$ \\
\hline
\end{tabular}

\begin{tabular}{|l|l|l|}
\hline $\begin{array}{l}\text { Alojamiento de Celda } \\
\text { individual }\end{array}$ & $\begin{array}{l}\text { Sin servicios de bie- } \\
\text { nes sanitarios }\end{array}$ & $5,4 \mathrm{~m} 2$ \\
\hline
\end{tabular}

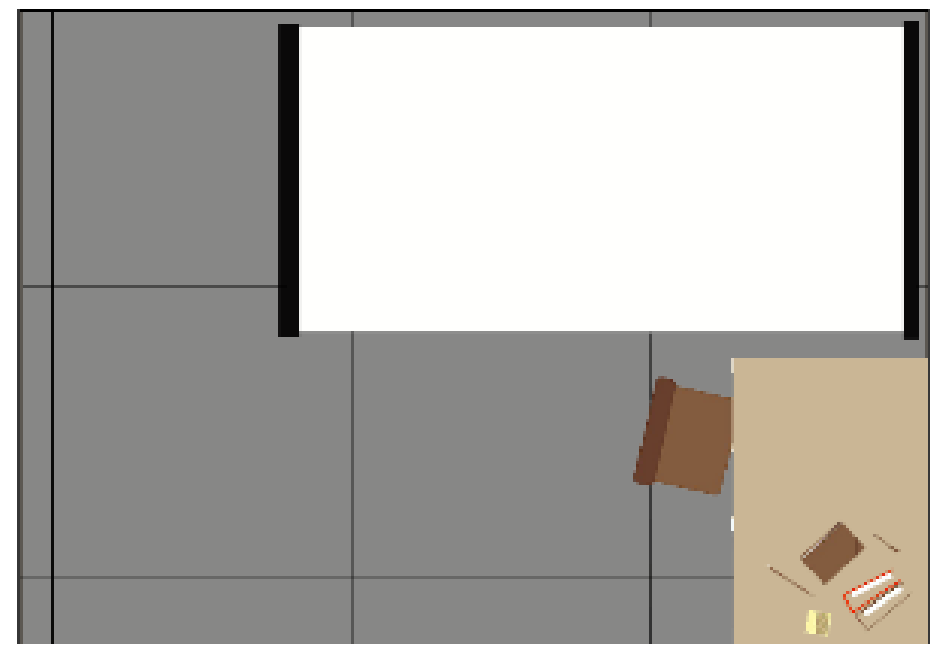

\begin{tabular}{|l|l|l|}
\hline $\begin{array}{l}\text { Alojamiento de celda } \\
\text { múltiple o compartida }\end{array}$ & $\begin{array}{l}\text { Con servicios de bie- } \\
\text { nes sanitarios, incluye } \\
\text { el espacio de la litera } \\
\text { (Camas) }\end{array}$ & Medida 3,4 m2 \\
Capacidad 10 reclusos \\
\hline
\end{tabular}

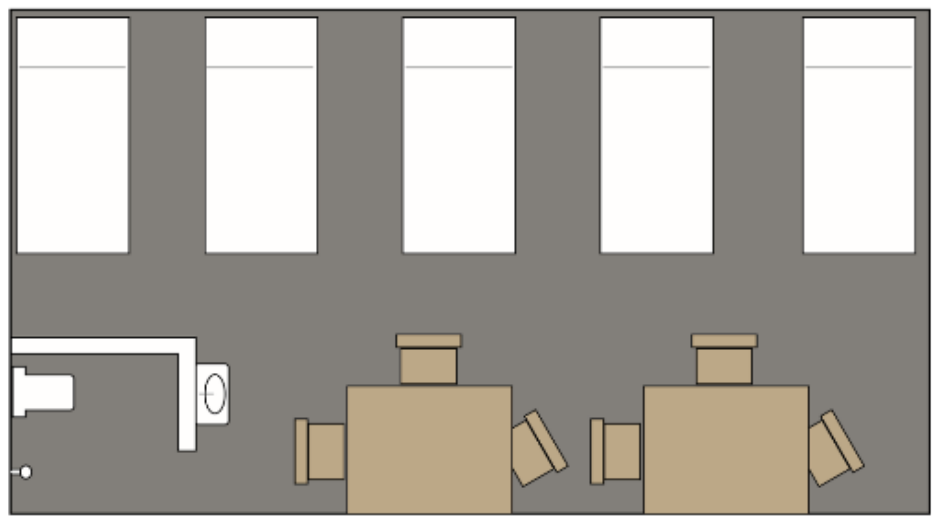


té de derechos económicos, sociales y culturales, valga mencionar, en los puntos $6,8,10,15,17$ y 18 ; igualmente el derecho al agua suficiente es detallado en otro informe $\mathrm{N}^{\circ} 15$ de observación general en 2002 por el mismo comité.

Finalmente, las reglas 20, numerales 1, 2 y 26, numeral 1 literal a) de las Reglas mínimas para el tratamiento de los reclusos.

Así, respetar el derecho a alimentos adecuados y agua suficiente radica en cabeza del Estado. Es decir, si el Estado ha privado a los presos de la oportunidad de satisfacer por sí mismos sus necesidades básicas, es el Estado el que debe satisfacerlas.; Encontrándose los reclusos en esta imposibilidad para el goce efectivo de su derecho a la vida en condiciones dignas, tales prerrogativas no se pueden hallar en vilo por estar condenados, pues la reducción de la ración de alimentos adecuados y agua suficiente equivale a un castigo corporal y constituye una pena inhumana.

Uno de los materiales investigativos más importantes es el artículo especial "El derecho a la alimentación como derecho humano" de 2014. El objetivo de ese trabajo investigativo es resumir los principales planteamientos contenidos en los instrumentos internacionales relacionados con ese derecho. Entonces esclarece de acuerdo con instrumentos y con las reflexiones que se han dado en el marco del sistema internacional de derechos humanos, en qué consiste el derecho a la alimentación adecuada, cuáles son las garantías que lo harán posible, cuáles son las obligaciones de los Estados, qué medidas deben adoptar estos para que efectivamente se realice y cuáles son los mecanismos para poder exigirlos y hacer justicia por medio de estos (Jusidman, 2014).

El trabajo de Luis Miguel Hoyos Rojas y Laura Cera Rodríguez, en su artículo "El derecho humano al agua como reivindicación neoconstitucional del sistema internacional de los derechos humanos: un nuevo derecho constitucional en Colombia", nos permite comprender que mundialmente el derecho al agua es entendido como una necesidad indispensable para la vida, esencial para vivir dignamente a partir del objeto concreto de protección. Esta investigación tiene como finalidad explicar la mutación constitucional del "derecho al agua” como garantía fundamental, al concebirse como novación jurídica de un derecho ius-fundamental. Valga aclarar que los autores explican, a partir de argumentos internacionales, jurídicos, legales y doctrinales, la alteración (mutación) del simple imaginario del derecho al agua como servicio público a derecho fundamental. Finalmente, en sus conclusiones, retoman la importancia de la investigación del profesor Mario Peña Chacón (2003) al observar que sin agua no hay vida posible y que se trata de un derecho humano personalísimo, urbi et orbi, erga omnes, que debe ser acatado por cualquier sociedad y todo Estado. Para el autor Mathus Escorihuela (2006), resulta ser una condición esencial, previa, que condiciona la existencia y el ejercicio de cualquier otro derecho humano (Mathus Escorihuela, 2006, pág. 225) 


\section{f) Derecho al vestido y a la ropa de cama}

El vestido como componente del derecho a un nivel de vida adecuado, es un derecho humano. Todos los presos a los que no se les permita llevar sus propias ropas, recibirán ropas adecuadas y dispondrán de medios para mantener la ropa limpia y en buenas condiciones.

La salud general de todos los presos que reciban una cama individual debe ir acompañada también de medios para mantener limpia la ropa de cama., con mecanismos y medios para lavar y secar regularmente la ropa de vestir y la ropa de cama.

Dichas prerrogativas legales se encuentran amparadas en el parágrafo 1 del $\operatorname{art}^{\circ} 11$ del Pacto Internacional de Derechos Económicos, Sociales y Culturales; las reglas 17 numeral 1, 2 y 3; la 18 y 19 numeral 1 literal d) de las Reglas mínimas para el tratamiento de reclusos.

En Colombia, los presos pueden llevar sus propias ropas, sin embargo, deben mudarse periódicamente sus prendas de vestir personales. Para ello, debe haber dentro o fuera del establecimiento medios para lavar y secar la ropa de la prisión.

En un Estado social de derecho debe permitírsele a los familiares de los presos proporcionar mudas regulares de vestimenta y ropa de cama limpia, ya que por la sobreocupación que presenta actualmente la mayoría de nuestros centros penitenciarios es inevitable. Con esta medida se busca tratar el equilibrio de la dignidad humana afectada por el hacinamiento.

\section{g) Derechos de los presos en materia de salud}

El disfrute del más alto nivel de salud física y mental es un derecho humano.

Lo manifestado está reconocido en el parágrafo 1 del $\operatorname{art}^{\circ} 12$ del Pacto Internacional de Derechos Económicos, Sociales y Culturales; sin dejar de un lado que la carta magna materializa este derecho humano a título de derecho fundamental de carácter autónomo.

El estado de salud, tanto físico como mental, de todo ser humano influye en la forma como se proyecta, trabaja, vive y se comporta. Esto es real para el personal del penitenciario como para los reclusos.

Así mismo, el estado de salud de una persona puede influir en otras personas y los enfermos necesitan cuidados especiales, no pueden contribuir plenamente a la sociedad. De ahí que la salud mental y física puede afectar una proporción importante de los presos a través de actos violentos sin conciencia y la transmisión de enfermedades a otras personas se da constantemente. Además hay una alta prevalencia del VIH/SIDA y la tuberculosis. 
Un claro ejemplo de ello es la investigación que se llevó a cabo en el Establecimiento penitenciario y carcelario de alta seguridad de Cómbita, Boyacá (Colombia) en la prestación del servicio de la EPS en materia de salud, en el tratamiento y remisión con especialistas de todas las áreas, cirugías, odontologías, otorrinolaringología y urología. Igualmente, la puesta en marcha de algunos proyectos, como la construcción de hospitales al interior de las penitenciarías, se ha quedado en una idea más de la política penitenciaria, pero sin aplicación concreta en una de las posibles soluciones a este problema. (Saenz, 2013)

El trabajo es de carácter inédito y de metodología documental y descriptiva. En este se busca demostrar que el autodenominado comité de presos políticos que actúa en el centro de reclusión de Boyacá construye su pensamiento filosófico como una consecuencia lógica de la vulneración de derechos humanos. Igualmente, critica y da como resultado de la investigación el cotejo entre la realidad y el supuesto normativo positivado de la prestación de la salud al interior del establecimiento carcelario, y termina proponiendo que la posible solución al sistema actual penitenciario y carcelario es la inclusión de políticas públicas que contextualicen la realidad social y la problemática económica en la política criminal estatal vigente.

En esta discusión, la salud de los centros penitenciarios interesa a todos, pues existe una inmensa mayoría de personas que visitan a los presos, al igual que el penitenciario que va de una cárcel a otra, donde puede afectar la salud de la comunidad. A estas alturas no hay duda de proteger la estabilidad de la salud constituye un real derecho humano, cuando el personal penitenciario está sano, trabajará mejor; cuando los presos están sanos, están más capacitados para trabajar y en mejores condiciones para sobrellevar la privación de libertad.

\section{h) Reconocimiento médico de los nuevos reclusos}

Todos los reclusos deben ser sometidos a un examen médico en cuanto ingresen a un centro de detención, el cual deberá ser de carácter gratuito y para garantizar la salud, todos los presos tendrán el derecho a solicitar una segunda opinión médica.

Situaciones señaladas en los principios 24 y 25 del Conjunto de principios para la protección de todas las personas sometidas a cualquier forma de detención o prisión, dando origen a la necesidad de una supervisión y un tratamiento médico sostenible materializado y confirmado en la regla 24 de las Reglas mínimas para el tratamiento de los reclusos, capítulo 4.

El propósito de someter a un reconocimiento médico a los nuevos presos durante su ingreso es velar por su salud, mas no obrar por el interés de las entidades penitenciarias. El Estado, por privar a una persona de su libertad, tiene la obligación de cuidar de ella, y este deber constitucional se extiende a 
la atención de salud ya que por encima de la legalidad y la normatividad está la vida como fundamento de todo el sistema jurídico, político y axiológico.

En Colombia, de acuerdo con la Organización de las Naciones Unidas (ONU, 2001) resalta en su informe sobre "Centros de reclusión en Colombia: un estado de cosas inconstitucional y de flagrante violación de derechos humanos", que generalmente las características sociodemográficas de la población carcelaria se corresponden con las de los grupos más vulnerables de la sociedad, pues son provenientes de zonas geográficas desfavorecidas; atendidos con muy bajo nivel de servicios básicos antes de ingresar a un centro de detención, razón suficiente para someterlos a un reconocimiento médico dado que ingresan a los centros de reclusión. (Martínez, Tidball-Binz, \& Yrigoyen Fajardo, 2001, pág. 29)

\section{i) Derecho de acceso a la atención de salud}

Las personas bajo custodia carcelaria son particularmente vulnerables en su derecho a la atención de salud, en tales casos todos los presos o detenidos tienen derecho al más alto grado posible de salud física y mental. Los presos deben tener acceso gratuito a los servicios de salud disponibles en el país; así pues, la garantía internacional de atención a la salud implica que, además de brindarse los tratamientos médicos disponibles para proteger la salud en estado de reclusión, también se deben tomar buenas decisiones al contratar personal calificado bajo criterios médicos.

La manifestación por excelencia de este derecho se plasma en el parágrafo 1 del art. 25 de la Declaración Universal de los Derechos Humanos; el parágrafo 1 del art. 12 del Pacto Internacional de Derechos Económicos, Sociales y Culturales; en el principio 9 de los Principios Básicos para el tratamiento de los reclusos; en las reglas 22, 23 y 25 (numeral 1 y 2) de las Reglas Mínimas para el tratamiento de los reclusos. Resaltando la regla 23 ya que se ocupa de necesidades médicas especiales para las mujeres en estado de reclusión con los niños recién nacidos.

No es viable el argumento de que una persona privada de su libertad tiene derecho a una atención sanitaria de peor calidad, ya que el Estado asume la responsabilidad de prestar una atención de salud adecuada, al limitar el derecho a la libertad individual.

Un producto del estudio de este derecho es el artículo académico realizado por Jennifer Hernández y Luz Mery Mejía (2010), "Accesibilidad a los servicios de salud de la población reclusa colombiana: un reto para la salud pública». En esta monografía se hizo una revisión bibliográfica junto a una recopilación sistemática de artículos publicados en revistas indexadas o en libros, trabajos de grado de maestría e información oficial de organismos nacionales e internacionales que hayan revisado el tema del servicio de salud en los centros penitenciarios de Colombia. 
En el trabajo se concluyó que en Colombia, a pesar de los mecanismos y acciones que se han llevado a cabo para mejorar la salud de esta población, el sistema de salud penitenciario aún presenta deficiencias que obstaculizan el acceso a los servicios de salud. El reto de la sociedad y del Estado es superar estos obstáculos y garantizar el acceso a los servicios de salud de la población reclusa que se entiende como altamente vulnerable. (Hernández \& L.M., 2010)

\section{j) Salubridad del lugar de reclusión}

El funcionario médico tiene la importante responsabilidad de velar porque se cumplan las debidas normas sanitarias. Por ello, resulta vital incluir control y vigilancia periódica de las condiciones de los alimentos, el agua, la higiene, la limpieza, el saneamiento, la calefacción, el alumbrado, la ventilación, las ropas y las camas de los reclusos y las oportunidades de hacer ejercicio.

Estas cuestiones han sido justificadas en las reglas 24 y 26, de esta última en su numeral 1 literal a), b), c), d) y e) de las Reglas Mínimas para el tratamiento de los reclusos.

De este modo, en el marco de los instrumentos internacionales aplicados a los reclusos en el punto relacionado con el entorno saludable, se exige la cooperación de todos en prisión, es decir: un adiestramiento sanitario para el personal y educación sanitaria para los presos. Por ello, es indispensable trabajar de la mano con los funcionarios de salud ambiental y pública para implementar las medidas necesarias, encaminadas a disminuir las afectaciones de los derechos humanos en los centros de reclusión.

\section{k) Atención de salud especializada}

Todas las cárceles deben tener instalaciones físicas sanitarias y personal médico adecuado para atender una amplia gama de necesidades de salud, incluida la atención dental y psiquiátrica. Aquellos presos a quienes no pueda brindárseles el tratamiento idóneo para las enfermedades mentales, en la cárcel, deben ser trasladados a un hospital civil o un hospital penitenciario especializado.

En efecto, en todos los centros especializados habrá servicios de diagnóstico y tratamiento psiquiátrico. En ningún caso los enfermos mentales pueden ser recluidos en prisiones sino transferidos a establecimientos especializados Estos aspectos están normalizados en las reglas 22 numeral 1, 2 y 3; la regla 82 numeral del 1 al 4 y la regla 83 de las Reglas Mínimas para el tratamiento de los reclusos.

Actualmente, en muchos sistemas jurídicos de los centros penitenciarios, existe una proporción considerable de reclusos que padecen algún tipo de enfermedad mental. Las personas que padezcan demencia deberán ser transferidas lo más pronto posible y lejos de los que están recibiendo tra- 
tamiento psiquiátrico y finalmente, se deberán adoptar disposiciones para que se prosiga su tratamiento una vez sean puestos en libertad.

Hay una serie de sentencias proferidas por la Corte Constitucional en defensa del derecho a la salud de la población reclusa en los centros penitenciarios. En estas se manifiesta el incumplimiento de la prestación de los servicios de salud, a pesar de las normas existentes, en sentencias tales como: la T-437/93 (derecho a la atención médica de las personas recluidas y protección del que está por nacer), la T-473/95(derecho a la salud del interno y su relación con el principio de dignidad humana), la T-535/98 (atención médica adecuada, digna y oportuna de los presos), la T-583/98 (acreditación de afectación y no atención para la procedencia de tutela por parte del interno frente a la vulneración enrostrada de su salud), la T-606/98 (parte fundamental del conjunto de prestaciones que en el plano del servicio médico deben asumir los establecimientos carcelarios, dando una oportuna práctica de los exámenes y pruebas técnicas para saber o descartar si la persona presente alguna afección de salud que afecte su capacidad física o mental), la T-607/98 (protección de la salud del interno por conexión con la dignidad humana u otros derechos fundamentales), la T-530/99 (protección de la salud del interno aunque no se encuentre en circunstancias extremas), la T-524/99 ( respuesta a la solicitud de traslado por graves riesgos de infección debido a trasplante de riñón como hecho notorio de la insalubridad y hacinamiento del centro penitenciario), la T-256/00 ( condiciones mínimas de higiene, salubridad y comodidad) y T 193/17 (posibilidad de fallar extra y ultra petita siempre que se establezca la infracción de un derecho fundamental del interno).

\section{1) Higiene}

Dentro de las cárceles todos los presos tendrán acceso a los medios atender sus necesidades fisiológicas de forma limpia y decente, manteniendo adecuadamente su propia limpieza y buen aspecto.

Esta base se consagra en los instrumentos internacionales en el parágrafo 1 del art. 12 del Pacto Internacional de Derechos Económicos, Sociales y Culturales; en las reglas 12, 13, 14, 15, 16 y 26 en el numeral 1 apartado b), de las Reglas Mínimas para el tratamiento de los reclusos.

La higiene es un elemento fundamental del derecho humano a la atención de salud en cantidad suficiente, es claro que en muchas cárceles grandes grupos de personas tienden a vivir durante periodos largos. Por ello es menester manifestar que es indispensable para la salud y la dignidad humana que los presos dispongan de los elementos para atender sus necesidades corporales básicas, con el debido grado de intimidad y vivir sin humillaciones.

Caso como el de David Antonio (Corte Constitucional, Sala , T-256, 2000), recluso de la Cárcel Bellavista, quien afirma que existen condicio- 
nes infrahumanas en los centros de reclusión, pues él tiene que dormir en el suelo del baño o en los pasillos, porque no ha tenido dinero para comprar un camarote. Debido a esto, se ha contagiado de enfermedades que ha debido soportar sin la necesaria atención médica, pues la cárcel no cuenta con un servicio eficiente. Todo esto se debe al hacinamiento que se vive en el penal. La Directora Regional Noroeste del INPEC responde que la Cárcel del Distrito Judicial de Medellín fue construida para 1.500 internos y que, con las adecuaciones posteriores, se dieron 300 cupos más. Actualmente están recluidas 5.836 personas.

Finalmente, la sala encuentra que efectivamente se están vulnerando derechos fundamentales del peticionario, los cuales deben ser protegidos de forma inmediata, independientemente de los programas que se desarrollan para el mejoramiento de nuestro sistema carcelario y que debe estar adelantando el Ministerio de Justicia en cumplimiento de lo ordenado por esta Corporación en Sentencia T-153 de 1998.

\section{m) Ejercicio}

Actividad física. Desde el primer momento, todos los presos pueden disponer de al menos una hora diaria para realizar ejercicio al aire libre, si las condiciones atmosféricas lo permiten.

Derecho humano que se relaciona con la dignidad humana y está consignado en el parágrafo 1 del art. 12 del Pacto Internacional de Derechos Económicos, Sociales y Culturales; en la regla 21 numeral 1 y 2 de las Reglas Mínimas para el tratamiento de los reclusos.

Finalmente, diversos trabajos investigativos demuestran que el ejercicio es fundamental para la buena salud física de los reclusos ya que es también una oportunidad social para disminuir la tensión menta. Se resalta su importancia para los presos nuevos o jóvenes.

\section{n) La seguridad en los centros penitenciarios}

En definitiva, solo se recurrirá al uso de la fuerza, incluido el empleo de armas de fuego, para impedir una fuga. Las medidas de corrección podrán utilizarse como herramientas de precaución contra una evasión durante un traslado, siempre y cuando sean retiradas las armas cuando esté se esté frente a una autoridad judicial, administrativa o por cuestiones médicas. En este orden de ideas, queda prohibido utilizar los mecanismos de coerción como castigo, o la implementación de cadenas y grillos como medios de coerción.

Este precepto legal guarda sustento jurídico en el principio 9 de los Principios Básicos sobre el Empleo de la Fuerza y de Armas de Fuego por los Funcionarios Encargados de hacer cumplir la Ley; en la regla 33 en su literal a) de las Reglas Mínimas para el tratamiento de los reclusos. 
Una vez revisada la regulación internacional, el concepto de seguridad no se limita a las barreras físicas para evitar la evasión; la seguridad también gira en torno al personal que tiene relación con los presos, pues deben estar alerta y al tanto de lo que suceda, velando porque los reclusos se mantengan activos de forma positiva.

Sin embargo, dependiendo de las características propias del delito y del individuo privado de la libertad, las instituciones carcelarias podrán y tendrán que retener en prisiones de alta, mediana o baja seguridad, según sea el caso. Asimismo, dentro de los establecimientos carcelarios no se puede desconocer que en el grado medio de seguridad a veces hay presos que deberían pertenecer al espacio de alta seguridad y entonces el individuo representa una grave amenaza para la población.

\section{Bajo este criterio resultan viables ciertas condiciones de se- guridad tales como:}

a. El tipo de instalaciones en la que esté retenido.

b. Las disposiciones que se adoptan cada vez que circula dentro del centro penitenciario o ha de ser escoltado fuera de él.

La seguridad dinámica conocida como una relación estrecha entre recluso y oficial penitenciario no consiste solamente en impedir que escape; sino también en el mantenimiento de las buenas relaciones con los presos, al punto de conocer el ánimo y temperamento del sujeto.

\section{n) Orden y control}

Por regla general, las prisiones deben ser entornos seguros para todos los que viven, trabajan y pasan por ellas, es decir, para los reclusos, el personal y los visitantes. Luego el orden y la disciplina se deben mantener con firmeza, para que nadie en prisión tema por su seguridad física, claro está, sin imponer medidas más restrictivas de las necesarias para mantener la seguridad y la buena organización de la vida en común. El texto anterior descansa en los artículos 1 y 16 de la Convención contra la Tortura o Penas Crueles, Inhumanas o Degradantes; en las reglas 27, 33 en su literal b) y c) y 34 de las Reglas Mínimas para el tratamiento de los reclusos.

Es natural que las personas acusadas o culpables de infringir la ley probablemente estén asustadas y se sientan amenazadas por estar en la cárcel con otros en condiciones similares pues también quebrantaron la ley. Por ello, la mayoría de los presos responderán positivamente si se les brinda un trato decente y humano.

Todo funcionario de prisiones con experiencia sabe que los medios de coerción y control no son suficientes para garantizar el orden. 


\section{o) Disciplina y castigo}

De vez en cuando, algunos reclusos se niegan a observar el reglamento legítimo, de ahí que todas las infracciones y las sanciones correspondientes deban estar especificadas por la ley o en reglamentos legales publicados. Ningún recluso será sancionado sin haber sido informado de la infracción que se le atribuye y sin que se le haya permitido previamente presentar su defensa. Bajo esta línea, las penas corporales, como el encierro en una celda oscura, así como toda sanción cruel, quedarán completamente prohibidas., Sin embargo, las penas de aislamiento y reducción de alimentos solo se aplicarán cuando el galeno haya certificado por escrito que puede soportarlas.

De igual forma, toda persona, sometida a medidas disciplinarias o presa, tendrá derecho a solicitar examen de esa decisión a autoridades.

Los parámetros de disciplina y castigo se enmarcan en la regla 28 numeral 1, en la regla 29 en el literal a), b) y c); en la regla 30 numeral 1, 2, y 3; en la regla 31 , en la regla 32 numeral 1, 2 y 3 y por último, en la regla 33 de las Reglas Mínimas para el tratamiento de reclusos. Asimismo, en el parágrafo 2 del principio 30 del Conjunto de Principios para la protección de todas las personas sometidas a cualquier forma de detención o prisión; en el principio 3 de los Principios de ética médica aplicables a la función del personal de salud, especialmente los médicos, en la protección de personas presas y detenidas contra la tortura y otros tratos o penas crueles, inhumanos o degradantes; en el principio 7 de los Principios básicos para el tratamiento de los reclusos; en el Pacto Internacional de Derechos Civiles y Políticos en el parágrafo 3 de su art. 8 en sus literales a), b) y c).

Al analizar la dimensión de los instrumentos internacionales es importante que los presos conozcan las normas que guían el conducto regular del centro penitenciario. Además deben reconocer que en caso de infracción a esos preceptos jurídicos se iniciará el procedimiento establecido en las disposiciones legales y de hallarse culpable, podrá ser sometido a una gama de penas que estarán establecidas en el mismo conjunto de procedimiento. Es claro que los principios de la justicia natural deben aplicarse a los procedimientos internos de la acción disciplinaria que se adelante en los centros de reclusión.

\section{p) Dar el mejor uso posible a las prisiones}

En este momento, la finalidad principal de las autoridades penitenciarias en el tratamiento de los reclusos debe ser alentar la reforma personal y la readaptación social. En resumen, el ideal final del régimen penitenciario debe ser ayudar a los reclusos a vivir conforme a la ley y de forma autónoma después de su liberación.

Esta finalidad se aferra en el art. 10 del Pacto Internacional de Derechos Civiles y Políticos en su artículo 3; en las reglas 65 y 66 de las Reglas Mínimas para el tratamiento de los reclusos. 
En última, las instituciones penitenciarias están facultadas para adoptar todas las medidas necesarias para que los presos no evadan la custodia legítima y en las cárceles reine el orden. Adicionalmente, la penitenciaría tiene la obligación de dar a los reclusos oportunidades para aprovechar debidamente el tiempo que pasan en custodia, es decir, debe existir un programa completo de actividades que comprenda la educación, la formación personal, el trabajo y la educación física para magnificar su dignidad humana y posibilitar la resocialización.

\section{q) Trabajo}

Permitir a todos los reclusos ser aptos desde el punto de vista médico para trabajar. El trabajo se materializa como derecho humano pues contribuirá a que puedan ganarse la vida honradamente después de su deliberación.

Por lo anterior, en aras de proteger este derecho humano, los reclusos deberán recibir una contraprestación económica por el trabajo que realicen. Igualmente, pertenecen a la legislación nacional en materia de salud y seguridad del trabajo y por lo tanto, están en las mismas condiciones de la comunidad civil no privada de su libertad personal.

Otro elemento esencial del derecho al trabajo es que se les permita a los presos que gasten al menos un parte de sus ingresos, que envíen una parte a su familia y que ahorren la otra parte.El diseño de los contenidos normativos que regulan el derecho humano al trabajo se contempla, en el art. 23 de la Declaración Universal de los Derechos Humanos; en el art. 8 en sus literales a), b) y c) del Pacto Internacional de Derechos Civiles y Políticos; en el principio 8 de los Principios Básicos para el tratamiento de los reclusos y por último en las Reglas Mínimas para el tratamiento de los reclusos en su art. 71 numeral del 1 al 6, en su artículos 72, 73, 74 y 75 en sus numerales 1 y 2 , en su $\operatorname{art}^{\circ} 76$ numeral del 1 al 3 .

Para la Organización de las Naciones Unidas, el desarrollo humano es un proceso de expansión de las libertades efectivamente disfrutadas por las personas, de ahí que los elementos internacionales distinguen entre "trabajos forzados" que pueden ser impuestos en cumplimiento de una orden judicial y "trabajo forzoso u obligatorio" que está prohibido.

Finalmente, los presos deben recibir un salario equitativo, en la medida en que, si los presos no tienen trabajo y se acostumbran a estar ociosos, pueden disminuir su sentido de responsabilidad respecto de sí mismos y sus familias. Esto puede poner en peligro los fines esenciales de la pena, ya que sin empleo, sería más difícil llevar una vida respetuosa de la ley tras su liberación.

\section{r) Educación y actividades culturales}

Estas actividades van dirigidas al pleno desarrollo de la personalidad humana, con todas sus implicaciones y consecuencias. Es evidente que en los centros penitenciarios se deben proporcionar actividades educativas y 
culturales, incluido el acceso a una biblioteca adecuada.

Es así como la educación en estado de reclusión debe orientarse al desarrollo de todas las persona, teniendo presente los antecedentes de orden social, cultural y económico. La participación de los analfabetos, tanto de los que no saben leer y escribir como de los que no están familiarizados con la tecnología y la de los reclusos jóvenes, es obligatoria y por ello, estas personas requieren de un énfasis y total atención. En dicho escenario, es importante la participación de la comunidad exterior para mejorar los vínculos de perdón y reconciliación con las personas privadas de la libertad.

Actividades fundamentales y dinámicas protegidas por el art. 26 parágrafo 1 y 2; por el art. 27 parágrafo 1 de la Declaración Universal de los Derechos Humanos; por el art. 13 del Pacto Internacional de Derechos Económicos, Sociales y Culturales; por el principio 6 de los Principios Básicos para el tratamiento de los reclusos; por las reglas 40, 77 y 78 de las Reglas Mínimas para el tratamiento de los reclusos. Cabe resaltar, en cuestión educativa en los establecimientos carcelarios, la resolución 1990 del 2000 del Consejo Económico y Social en su parágrafo 3 en su literales a) al j).

Por otro lado, los altos niveles de desempleo que padecen muchos países hace difícil encontrar empleo suficiente para los reclusos. Por esta razón, la educación en las prisiones adquiere aún más importancia.

La educación es el arma más potente contra la ignorancia; las actividades culturales generan alta confianza en sus capacidades, y proyectan a las personas para vivir en armonía con la ley apenas sean puestas en libertad. Finalmente, la educación y las actividades culturales ayudan a la integración social ya que evitan el deterioro mental y mejoran el nivel de instrucción en actividades como música, teatro, arte y actividades de ocio.

\section{s) Religión}

Elemento base de la libertad humana y convicción íntima para guiarse según sus propias características. Todo preso tiene derecho a seguir los preceptos de su religión y a tener acceso a un ministerio de esta, y no se puedes limitar a las religiones tradicionalmente aceptadas por las mayorías.

La libertad de creencia y culto protegida por el $\operatorname{art}^{\circ} 18$ de la Declaración Universal de los Derechos Humanos; por el art. 18 parágrafo 2 del Pacto Internacional de Derechos Civiles y políticos.

De acuerdo con lo anterior y pese a que las personas se encuentran en estado de reclusión, ciertos derechos no son absolutos, de ahí que la práctica de su propia religión, sea en privado o públicamente, pueda verse restringida. Por ese motivo, en Las Reglas Mínimas para el tratamiento de los reclusos en su art. 41 numeral 1, 2 y 3 y art. 42, se establecen los criterios mínimos y las recomendaciones para ejercer su libertad de credo. 
En diversos países, dentro de los sistemas penitenciarios varía la condición de un representante religioso, ya que se trata de un tema cultural, heredado de generación en generación y que cambia constantemente por la forma en que cada sujeto se apropia de ella y la experimenta. Por esta razón, en algunos países es permitido el ingreso de los representantes y en otros no.

Ahora bien, en contraste, algunos países solo permiten el ingreso a las prisiones de los representantes de la religión mayoritaria. Los reclusos de confesiones minoritarias no tienen autorización para ejercer los preceptos de su fe. Esto supone grave infracción de los instrumentos internacionales, pues limitarle a una persona su libertad de credo por el ejercicio de las mayorías, considerando que los proyectos de vida de las minorías son actos inmorales, es vulnerar los derechos humanos e irrespetar los principios y la filosofía que inspiraron la Declaración Universal de los Derechos Humanos.

Lo anterior comprende algunos paradigmas de la moral y el derecho, pues estas concepciones siempre van a estar en debate, al igual que los cultos religiosos. Pero tales maneras de pensar, actuar, comportarse o vivir en una sociedad pluralista, no pueden volverse principios fundamentales del derecho, ni como finalidad o idoneidad para restringir libertades ya adquiridas a través de la historia.

\section{t) Preparación para la puesta en libertad}

Desde el principio de la condena se tendrá en cuenta el porvenir del recluso después de su liberación y se le prestará apoyo para velar por su futura reincorporación a la sociedad. Dando por sentado que todos los organismos y servicios responsables de la reintegración de los reclusos en la sociedad velarán por los presos, se supone que ellos tendrán los medios y recursos a su disposición para subsistir durante el periodo que siga inmediatamente a su deliberación. Esta normatividad internacional se observa en el principio 10 de los Principios básicos para el tratamiento de los reclusos y las reglas ${ }^{\circ} 80$ y 81 de esta última en el numeral 1,2 y 3 de las Reglas Mínimas para el tratamiento de los reclusos.

Desde una mirada transdisciplinaria, los infractores de una disposición legal y encontrados culpables son enviados a prisión para ser castigados mediante la privación de la libertad durante cierto tiempo. La mayoría regresan a la comunidad civil una vez hayan cumplido su condena. Una tarea importante del personal penitenciario al igual que del juez de ejecución de penas consiste en preparar a los presos para vivir de acuerdo con el régimen constitucional vigente apenas queden en libertad. En este sentido, es preciso adoptar disposiciones especiales para la preparación de los reclusos que hayan cumplido penas muy largas, porque su estructura de apoyo en la comunidad puede haberse desorganizado o desaparecido.

En amplio reconocimiento de la preparación para la puesta en libertad 
definitiva, existen beneficios y sustitutos como los permisos domiciliarios y los arreglos de la libertad temporal vigilada, que permite a los reclusos empezar a acostumbrarse de nuevo al mundo exterior y a restablecer sus relaciones personales y laborales. Esos procedimientos también permiten ensayar la reacción del recluso a la vida en sociedad, antes de obtener de nuevo su derecho absoluto a la libertad.

Ahora bien, frente a. los beneficios y los sustitutos como sendero de la libertad definitiva cabe resaltar que se deben otorgar con los requisitos formales nacionales que haya establecido cada Estado a través del órgano legislativo e interpretados por el operador jurídico competente. Sin embargo, en un estado de cosas inconstitucionales, dichos requisitos formales, para el otorgamiento de determinadas prerrogativas legales y favorables, deberán flexibilizarse. Es decir, los criterios de los requisitos formales para obtener un beneficio o sustituto penal deben doblegarse en un Estado de cosas inconstitucionales para otorgar la libertad condicional. Y esta acción de flexibilizar no es solo razonable, sino imperativa, ya que en la situación que se encuentran los reclusos es poco probable el cumplimiento idóneo de los requisitos formales.

La Corte Constitucional ha declarado en tres oportunidades el estado de cosas inconstitucionales (T-153/98, T-388/13 y T-762/15) ante la violación masiva y sistemática de los derechos fundamentales de los reclusos. Para adoptar la primera de estas providencias se visitaron dos establecimientos carcelarios ubicados en Bogotá y Medellín. Allí se encontraron, entre otros hallazgos, pozos de aguas negras cerca de rebosar; la sección de enfermería y sanidad se encontraba destinada parcialmente para albergar presos con perfil de máxima seguridad, percibiéndose adicionalmente malos olores; los internos habitaban túneles húmedos y oscuros, que no tienen ventilación ni luz y los baños habían sido adaptados como dormitorios. Durante la visita nocturna se percibieron olores fétidos, poca ventilación y escasa iluminación; los internos dormían en los pasillos y en las letrinas, e incluso las personas que adelantaron la diligencia pisaron algunas cabezas de internos durante el transcurso de la inspección. (Hernández Jiménez, 2018)

Con base en lo anterior, el docente investigador ${ }^{7}$ concluyó que las condiciones en las que vivían los internos de estos establecimientos carcelarios eran inhumanas y no se compaginaban con el principio de dignidad humana, pues en estas condiciones no se puede cumplir en debida forma con los pre-

7 Norberto Hernández Jiménez. Docente investigador y miembro del grupo de investigación en derecho penal, derecho disciplinario y derechos humanos de la Universidad Libre (Colombia). Asesor docente del Grupo de Prisiones de la Universidad de los Andes (Colombia) y profesor de cátedra de la misma Universidad. Abogado, especialista y magíster en derecho penal de la Universidad Libre. Especialista en derecho constitucional y en derecho administrativo de la Universidad del Rosario (Colombia). Máster en criminología y ejecución penal de la Universitat Pompeu Fabra (España). Doctor en Derecho por la Universidad de los Andes. noherji@gmail.com. 
supuestos establecidos para el tratamiento penitenciario ${ }^{8}$. Adicionalmente, en el fallo de tutela se determinó que esta situación era no solo de estos establecimientos carcelarios, sino de todos los demás que integran el sistema penitenciario y carcelario colombiano. En los fallos judiciales se describen adicionalmente las falencias estructurales de la infraestructura carcelaria, ante la evidencia encontrada, que afecta tanto los servicios de acueducto y alcantarillado como el de electricidad. Dentro de este entorno se constata que (i) existe hacinamiento, (ii) no hay separación de los internos por categorías (con base en este aspecto se vulnera, además, la presunción de inocencia al no separar sindicados y condenados), (iii) no se cumple con la función de resocialización y (iv) impera la violencia.

En el año 2013, la Corte Constitucional analizó nueve expedientes de acción de tutela acumulados, que dieron lugar a la sentencia T-388 y T-762 de 2015, en los cuales se alegó nuevamente que la situación carcelaria del país y las condiciones de reclusión atentaban contra los enunciados constitucionales, entonces se declaró un nuevo estado de cosas inconstitucional, en el que «los derechos constitucionales de las personas privadas de la libertad son violados de manera masiva y generalizada". Para la Corte se trató, como se ha dicho, de un "nuevo" estado de cosas inconstitucional, ya que aquel que fue decretado en 1998 se entendía superado. No obstante, advirtió que no se debía a nuevos hechos sobrevinientes, sino a situaciones estructurales que se mantenían y se reiteraban.

A pesar de que la Corte comprobó la construcción efectiva de más cárceles, la crisis se mantuvo y se consideró que el hacinamiento no se resuelve únicamente con la construcción de más cupos carcelarios. La Corte planteó también la necesidad de "menos cárcel", es decir, menos uso del derecho penal como mecanismo de control social. En ese mismo orden de ideas explicó que la política criminal debe apuntar a un derecho penal entendido como última ratio; una política criminal que debe ser ante todo preventiva y propender a la resocialización.

Se advierte en esta sentencia que el Tribunal Constitucional le otorgó un papel fundamental en la conjuración de la crisis a una política criminal que ha de ser razonable, coherente, proporcional, sostenible y "sensible a los sujetos de especial protección constitucional que vean sus derechos fundamentales comprometidos por el Sistema penitenciario y carcelario".

La Corte afirmó que las dificultades que atraviesan los internos trascienden la dinámica de cada uno de los establecimientos y se "extienden a un nivel nacional del sistema penitenciario y carcelario". A partir de lo anterior, con-

8 Señala expresamente la Corte Constitucional que las cárceles colombianas se caracterizan: "por el hacinamiento, las graves deficiencias en materia de servicios públicos y asistenciales, el imperio de la violencia, la extorsión y la corrupción, y la carencia de oportunidades y medios para la resocialización de los reclusos" (Corte Constitucional, Sala, T-153, 1998). 
cluyó que la "crisis carcelaria" presente en Colombia se debe a unas "problemáticas que más que esporádicas son estructurales". Para explicarlas, se basó en gran medida en el diagnóstico y las consideraciones de la sentencia T-153 de 1998. Finalmente, vale la pena aclarar que las sentencias en citación afirman que las condiciones en las que se encuentra el sistema penitenciario, a nivel nacional en Colombia, no permite el proceso de resocialización de los internos. Esto se compagina con la retribución que lleva implícita la pena y la demanda de algunos sectores de la sociedad, en los que el efecto del delito tiende a ser "pudrirse en la cárcel" (Birckeck, 2003, pág. 44) (Garland, 2005, pág. 301) (Gerez Ambertín, 2009, pág. 513) (Pérez Toro, 2012, pág. 5). Tal resultado podría concretarse fácilmente en las condiciones en las que se encuentra el sistema penitenciario y carcelario colombiano.

Para terminar, es pertinente resaltar que la Corte invitó a diferentes universidades del país a acompañar a la Defensoría del Pueblo en el seguimiento de las órdenes de la sentencia y en el desarrollo de las denominadas normas técnicas para una reclusión digna, las cuales estarán a cargo del comité interdisciplinario. En las órdenes que involucran a los jueces de ejecución de penas.

Teniendo en cuenta el panorama anterior, resulta claro que si bien en la teoría la especial relación que nace entre la persona privada de la libertad y el interno conlleva a una protección de sus derechos fundamentales, en especial de la dignidad humana, en la realidad la declaratoria advierte que tales condiciones no se cumplen. Sobre éste punto, el Juez de Ejecución de Penas puede hacer un gran aporte. El señalamiento de la Corte Constitucional de una serie de órdenes para que se cumplan los derechos es un claro ejemplo de ello, y este es el aspecto al cual queremos llegar, para examinar en las decisiones cómo es posible la aplicación de éstos instrumentos.

En la institución de la prisión domiciliaria en la que luego de cumplir los requisitos objetivos del artículo 38 del código penal y en especial frente a los requisitos del 38B sobre el arraigo, siendo éste concepto el lazo que puede unir a una persona a un determinado lugar o grupo social, familiar, laboral; la indeterminación del lugar donde tiene el arraigo a la hora de la decisión no puede obstaculizar la concesión de la gracia de dicho sustituto, por cuanto al momento de la suscripción de la diligencia de compromiso lo puede adjuntar.

Ahora bien, existe un aspecto de demora para conceder este sustituto y es la verificación, que en oportunidades se realiza sobre el sitio donde el sentenciado ha solicitado la prisión domiciliaria. En lugar de ello, basta con la información que suministre al momento de pretenderla, por lo que se debe aplicar el principio de buena fe y dejarle al INPEC la labor de verificación, cuando realice las visitas. A excepción de que se trate de un delito de violencia intrafamiliar, en tal caso es ideal que no se fije la residencia en un lugar cercano al de la víctima. 
En los casos de habitantes de la calle o las personas de la tercera edad, los primeros no cuentan con un sitio determinado y los segundos tampoco, porque su familia no los quiere o no los puede recibir dadas sus condiciones de dependencia.

Para estas situaciones lo más aconsejable es establecer las condiciones en las que se encuentra el Centro de Reclusión (hacinamiento, salud, alimentación). Como en la mayoría de los casos no son favorables, el Juez de Ejecución de Penas en asociación con el asistente social, debe buscar un centro de atención para habitantes de la calle u hogar de paso, donde le ofrezcan al sentenciado condiciones para sobrellevar el resto de condena. Lo mismo con las personas de la tercera edad, en tal situación no se puede dejar de lado que se trata de quién goza de especial protección constitucional.

Respecto a la suspensión condicional de la ejecución de la pena, $\left(63 \mathrm{CP}^{9}\right)$, que permite una vez superados los requisitos, teniendo en cuenta los antecedentes penales dentro de los cinco años anteriores, deberá estudiarse su conveniencia.; Es igualmente necesario tener en cuenta las condiciones de las cárceles en Colombia, el hacinamiento y las condiciones de salubridad. En caso de que el condenado padezca de diabetes o insuficiencia cardiaca o cualquier otra patología que sin ser grave y se advierta que sus condiciones de salud van a sufrir un franco deterioro porque el suministro de salud es deficiente, al igual que las condiciones de higiene y de las celdas, es necesario anteponer sus condiciones de salud que junto con los de la prisión no van a ser las más adecuadas y priorizar la dignidad del sentenciado.

En cuanto a la libertad condicional, el cumplimiento del requisito objetivo debe ser el único obligatorio porque la valoración de la conducta punible no debe ser otra que la realizada por el juez sentenciador a voces de la C-757 de 2014, de cara al adecuado desempeño y comportamiento durante el tratamiento penitenciario y desde luego, a las condiciones en las que se encuentre el sentenciado en el centro de reclusión. Juega entonces un papel importante el análisis desde la perspectiva que suministran los instrumentos internacionales de la salud e higiene en las situaciones en las celdas y desde luego el hacinamiento.

El Juez de ejecución de penas debe conocer estas condiciones bien sea por la información que suministre el interno o por las que de manera inmediata pueda conocer. Para ello, las visitas a las cárceles se convierten en una importante herramienta, porque así puede observar las condiciones en las se encuentra el prisionero.

\section{CONCLUSIONES}

En síntesis, en las legislaciones actuales de Colombia es imposible cumplir con los fines esenciales de la pena, dado que está opera fundamen-

9 Ley 599 de 2000. Código penal colombiano. 
talmente en la fase de ejecución (Bacigalupo, 1978, p. 16) del interno en el centro de reclusión. Entonces las decisiones de los jueces de ejecución de penas deben estar atadas a las condiciones que el convicto tenga en el lugar de reclusión y debe flexibilizar los análisis que tengan que ver con los aspectos subjetivos anteponiendo el principio fundante del Estado social de derecho: la dignidad humana. Pues en muchas oportunidades, por lo menos dentro del ambiente nacional Colombiano, los programas de prevención del delito y reeducación son insuficientes, obsoletos y poco efectivos, cumpliendo así la sanción penal (pena) con funciones distintas a las encomendadas por el legislador y el constituyente, en el punto del proceso (Hernández Jiménez, 2018, pág. 554)

Por ende, es imposible en un estado de cosas inconstitucionales que las personas en reclusión puedan satisfacer con excelencia el fin último de la pena: "la resocialización". De ahí que las declaratorias realizadas por la Corte Constitucional sobre la situación de la población carcelaria en Colombia denuncien la imposibilidad del Estado de prevenir el delito de manera diferente a la utilización del derecho penal.

Deviene concluir que el Juez de Ejecución de Penas que deje de aplicar los instrumentos internaciones se convierte en coadyuvante de la injusticia y la pasividad del Estado frente al sufrimiento de las personas privadas de la libertad. Por lo tanto, en cada una de las decisiones debe primar la protección de los derechos humanos antes que el delito por el cual ha sido condenado.

\section{REFERENCIAS BIBLIOGRÁFICAS}

Afanador C, M. I. (2002). El derecho a la integridad personal. Elementos para su análisis. Reflexión política, 4(8), 92. Obtenido de https:// scholar.google.com/scholar_url?url=http://convergencia.uaemex. $\mathrm{mx} /$ article/download/1669/1264\&hl=es\&sa $=\mathrm{T} \& \mathrm{oi}=$ gsb-gga\&c$\mathrm{t}=\mathrm{res} \& \mathrm{~cd}=0 \& \mathrm{~d}=11021549063052851809 \& \mathrm{ei}=$ _wpJXPySKNKTmwHz25vQBA\&scisig $=$ AAGBfm0Oted5nedm̄Qhulsixs2c4wNVNJDA

Ariza, L. (2011). Reformando el infierno: los tribunales y la transformación del campo penitenciario en América Latina. Universidad de los Andes, 18-109.

Bello, J. A., \& Parra, G. (2016). Cárceles de la muerte: necropolítica y sistema carcelario en Colombia. Universitas Humanística, 365-391. doi:http://dx.doi.org/10.11144/Javeriana.uh82.cmns

Birckeck, C. (2003). Tres enfoques necesarios para la victimología. Revista Cenipec (22), 33-66.

Chacón, M. (2003). Daño ambiental y prescripción. Revista Jurídica Lex. Difusión y Análisis, VII(93). Obtenido de https://escuelajudicialpj. poder-judicial.go.cr/Archivos/documentos/revs_juds/Revista\%20 
109/PDFs/07_danio_ambiental_prescripcion.pdf

Cifuentes Muñoz, E. (2001). Red de promotores de derechos humanos, derecho a la integridad. Obtenido de Defensoría del Pueblo: http://cdim.esap. edu.co/BancoMedios/Documentos\%20PDF/derecho\%20a\%20 la\%20integridad.pdf

de Dardel, J. (2015). Resistiendo la» nuda vida»: los prisioneros como agentes en la era de la Nueva Cultura Carcelaria en Colombia. Crítica Penal y Poder(8), 47-65. Obtenido de http://revistes.ub.edu/index.php/CriticaPenalPoder/article/view/9853

Drenkhahn, K. (2015). Las penas de larga duración y los derechos humanos -conclusiones de un estudio internacional-. Revista de Estudios de la Justicia(23), 107-144. doi:10.5354/0718-4735.2016.38978

Duarte, M., Paz, G., \& Sueldo, M. (14 de octubre de 2016). Derecho a la integridad personal en el sistema carcelario. Recuperado el 10 de enero de 2019, de Universidad Católica Argentina: http://bibliotecadigital.uca.edu.ar/ repositorio/contribuciones/derecho-integridad-personal-sistema.pdf

Enterría Martínez-Carande, E. G. (2002). El principio de protección de la confianza legítima como supuesto título justificativo de la responsabilidad patrimonial del Estado legislador. Revista de administración pública(159), 173-208. Obtenido de https://dialnet.unirioja.es/ descarga/articulo/293639.pdf

Galindo, J. A. (23 de octubre de 2009). Contendio del Derecho a la Integridad Personal. Rev. Derecho del Estado(23), 89-130. Recuperado el 20 de noviembre de 2018

Garland, D. (2005). La cultura del control: crimen y orden social en la sociedad contemporánea (Vol. 367). (Gedisa, Ed., \& M. Sozzo, Trad.) Oxford: Oxford University Press. Obtenido de http://www.antoniocasella. eu/nume/Garland_control_2001.pdf

Gerez Ambertín, M. (2009). Estrategias discursivas y políticas del dispositivo punitivo. I Congreso Internacional de Investigación y Práctica Profesional en Psicología XVI Jornadas de Investigación Quinto Encuentro de Investigadores en Psicología del Mercosur (págs. 511-515). Buenos Aires: Universidad de Buenos Aires. Obtenido de https://www.aacademica.org/000-020/31

Gómez Hermoso, R. (2009). Violencia en los comportamientos humanos. Valoración de la peligrosidad en presos reincidentes. Anuario de Psicología Jurídica, 19, 43-60. Obtenido de https://www.redalyc. org/html/3150/315025340005/

Hernández Jiménez, N. (2018). La resocialización como fin de la pena-una frustración en el sistema penitenciario y carcelario colombiano-. Caderno CRH, 30(18), 539-559. Obtenido de https://portalseer. ufba.br/index.php/crh/article/view/20034 
Hernández, J., \& L.M., M. (2010). Accesibilidad a los servicios de salud de la población reclusa colombiana: un reto para la salud pública. Facultad Nacional de Salud Pública(28), 32. Obtenido de http://revistaestudiospoliticos.udea.edu.co/index.php/fnsp/article/view/4771

Into, P. T. S. (2002). Comparación de factores psicosociales y estrés post-traumático en internos y empleados de cinco centros penitenciarios: un estudio exploratorio. Anuario de psicología jurídica(12), 69-85. Obtenido de https://journals.copmadrid.org/apj/archivos/80164.pdf

Jusidman-Rapoport, C. (2014). El derecho a la alimentación como derecho humano. salud pública de méxico, 56, 86-91. Obtenido de http://www. scielo.org.mx/scielo.php?pid=S0036-36342014000700013\&script $=$ sci_abstract\&tlng $=$ en

Martínez, F., Tidball-Binz, M., \& Yrigoyen Fajardo, R. (2001). Centros de reclusión en Colombia: un estado de cosas inconstitucional y de flagrante violación de derechos humanos. Revista de Derecho Penal, 29.

Mathus Escorihuela, M. (2006). El derecho al agua en el Derecho Argentino. Thomson Reuters-Aranzadi., 221-250.

Mayer, O. (1982). Derecho administrativo alemán. Buenos Aires: Depalma.

Mbembe, A. (2011). Necropolítica. España: Editorial Melusina.

Nembrini, P. G. (2011). Agua, saneamiento, higiene y hábitat en las cárceles. Ginevra: Comité Internacional de la Cruz Roja.

Pérez Toro, W. (2012). ¿Nos repugna realmente la prisión? Un recordatorio abolicionista. Revista diálogos de derecho y política (9), 1-18. Obtenido de http://aprendeenlinea.udea.edu.co/revistas/index.php/ derypol/article/view/12319/11168

Rovira, D. P. (2002). Clima emocional en las organizaciones: dos estudios en centros penales. Suma psicológica(9), 157-192. Obtenido de https://dialnet.unirioja.es/servlet/articulo? codigo $=4512215$

Ruiz, J. I. (1999). Estrés en prisión y factores psicosociales. Revista Colombiana de psicología(8), 120-130. Obtenido de https://revistas.unal. edu.co/index.php/psicologia/article/view/16097

Sáenz Dávalos, L. (2015). Apuntes sobre el derecho a la integridad en la constitución Peruana. Revista de derecho constitucional(1), 293-301.

Saenz, D. A. (2013). Derechos Humanos Sistema Penitenciario y Presos Políticos en Colombia estudio de Caso: Establecimiento Penitenciario y Carcelario de Alta Seguridad de Cómbita - Boyacá. Principia Iuris(19), 19. Obtenido de http://revistas.ustatunja.edu.co/index. $\mathrm{php} /$ piuris/article/view/772 
Salomoni, J. L. (1997). La cuestión de las relaciones de sujeción especial en el Derecho público argentino. Problemática de la Administración Contemporánea.

Solórzano Betancourt, M. A. (diciembre de 2010). El Programa de Derechos Humanos del Distrito Federal (PDHDF) en materia de Derechos de las Personas con Discapacidad. Recuperado el 21 de diciembre de 2018, de MSyE-PDHDF, México.: https://www.equipopueblo.org.mx/descargas/folletospdf/integridad.pdf

UNODC. (1996). Recopilación de reglas y normas de las Naciones Unidas en la esfera de la prevención del delito y la justicia penal. Obtenido de Condiciones Penitenciarias en Africa: http://elearning.icrc.org/detention/es/story_content/external_files/Condiciones\%20Penitenciarias\%20en\%20Africa\%20(1996).pdf

Wacquant, L. J. (2010). Castigar a los pobres: el gobierno neoliberal de la inseguridad social. Barcelona: Gedisa.

\section{JURISPRUDENCIA}

Corte Constitucional, Sala Cuarta de Revisión de Tutelas. (1993) Sentencia T-437. [MP Carlos Gaviria Díaz] Obtenido de: http://www. corteconstitucional.gov.co/relatoria/1993/T-437-93.htm

Corte Constitucional, Sala Octava de Revisión de Tutelas. (1995) Sentencia T-473 [MP Fabio Moron Diaz] Obtenido de: http://www. corteconstitucional.gov.co/relatoria/1995/t-473-95.htm

Corte Constitucional, Sala Tercera de Revisión de Tutelas. (1998) Sentencia T-153 [M.P Eduardo Cifuentes Muñoz] Obtenido de: http:// www.corteconstitucional.gov.co/relatoria/1998/T-153-98.htm

Corte Constitucional, Sala Quinta de Revisión de Tutelas. (1998) Sentencia T-535 [M.P José Gregorio Hernández Galindo] Obtenido de: http:// www.corteconstitucional.gov.co/relatoria/1998/T-535-98.htm

Corte Constitucional, Sala Quinta de Revisión de Tutelas. (1998) Sentencia T-583 [M.P José Gregorio Hernández Galindo] Obtenido de: http:// www.corteconstitucional.gov.co/relatoria/1998/T-583-98.htm

Corte Constitucional, Sala Quinta de Revisión de Tutelas. (1998) Sentencia T-606 [M.P José Gregorio Hernández Galindo] Obtenido de: http:// www.corteconstitucional.gov.co/relatoria/1998/T-606-98.htm

Corte Constitucional, Sala Quinta de Revisión de Tutelas. (1998) Sentencia T-607 [M.P José Gregorio Hernández Galindo] Obtenido de: http:// www.corteconstitucional.gov.co/relatoria/1998/T-607-98.htm

Corte Constitucional, Sala Novena de Revisión de Tutelas. (1999) Sentencia T-530 [M.P Vladimiro Naranjo Mesa] Obtenido de: http:// www.corteconstitucional.gov.co/relatoria/1999/t-530-99.htm 
Corte Constitucional, Sala Quinta de Revisión de Tutelas. (2000) Sentencia T-256 [M.P José Gregorio Hernández Galindo] Obtenido de: http:// www.corteconstitucional.gov.co/relatoria/2000/t-256-00.htm

Corte Constitucional, Sala Novena de Revisión de Tutelas. (2001) Sentencia T-879 [M.P Clara Inés Vargas Hernández]. Obtenido de: http:// www.corteconstitucional.gov.co/relatoria/2001/t-879-01.htm

Corte Constitucional, Sala Tercera de Revisión de Tutelas. (2004) Sentencia T-851 [M.P Manuel José Cepeda Espinosa] Obtenido de: http:// www.corteconstitucional.gov.co/relatoria/2004/t-851-04.htm

Corte Constitucional, Sala Tercera de Revisión de Tutelas. (2004) Sentencia T-1096, M.P Manuel José Cepeda Espinosa. Obtenido de: http:// www.corteconstitucional.gov.co/relatoria/2004/t-1096-04.htm

Corte Constitucional, Sala Sexta de Revisión de Tutelas. (2006) Sentencia T-439 [M.P Marco Gerardo Monroy Cabra] Obtenido de: http:// www.corteconstitucional.gov.co/relatoria/2006/t-439-06.htm

Corte Constitucional, Sala Segunda de Revisión de Tutelas. (2009) Sentencia T-412 [M.P María Victoria Calle Correa]. Obtenido de: http:// www.corteconstitucional.gov.co/relatoria/2009/T-412-09.htm

Corte Constitucional, Sala Primera de Revisión de Tutelas. (2013) Sentencia T-388 [M.P María Victoria Calle Correa]. Obtenido de: http:// www.corteconstitucional.gov.co/relatoria/2013/t-388-13.htm

Corte Constitucional, Sala Plena (2014) Sentencia C-757 [M.P Juan David Correal Rodríguez] Obtenido de: http://www.corteconstitucional.gov.co/relatoria/1993/T-437-93.htm

Corte Constitucional, Sala Quinta de Revisión de Tutelas. (2015) Sentencia T-762 [M.P Gloria Stella Ortiz Delgado]. Obtenido de: http:// www.corteconstitucional.gov.co/relatoria/2015/t-762-15.htm

Corte Constitucional, Sala Sexta de Revisión de Tutelas. (2017) Sentencia T-193 [M.P. Iván Humberto Escrucería Mayolo]. Obtenido de: http:// www.corteconstitucional.gov.co/relatoria/2017/T-193-17.htm

\section{NORMAS}

Colombia, Asamblea Nacional Constituyente, Constitución Política de 1991.

Colombia, Congreso de la República, ley 65 de 1993 (Código Penitenciario y Carcelario).

Colombia, Congreso de la República, ley 599 de 2000 (Código penal).

Colombia, Congreso de la República, ley 906 de 2004 (Código de Procedimiento penal). 